DOI: 10.5824/1309-1581.2018.1.005.x

http://www.ajit-e.org/?menu=pages\&p=details_of_article\&id=272

Received : 15.11.2017_Editorial Process Begin: 09.02.2018Ｐublished: 12.02.2018

\title{
Lokasyon Bazlı Pazarlama Açısından Sosyal A ̆g Uygulamalarının Kullanımı: Swarm Kullanıcıları Üzerine Bir Araştırma
}

Adnan DUYGUN, İstanbul Gelişim Üniversitesi, İktisadi İdari ve Sosyal Bilimler Fakültesi, Yrd. Doç. Dr., aduygun@gelisim.edu.tr, https://orcid.org/0000-0003-4026-4054

Öz

\begin{abstract}
Gelişen ve değişen dijital teknolojiye bağhl olarak pazarlama stratejileri de dijital platformda kendine yer bulmaktadır. Internetin cep telefonlarında yaygın bir şekilde kullanılmaya başlaması ile birlikte mobil bazl uygulamalarm pazarlama literatürüne eklediği kavramlardan biri de lokasyon bazh pazarlamadır. Bu çalı̧̧mada, lokasyon bazh pazarlama açısından sosyal ă̆ uygulamalarının kullanımı incelenmiştir. Foursquare, Google Plus, Gypsii, Plazes ve Facebook gibi sosyal ă̆ uygulamalarn olsa da son dönemlerde en popüler sosyal ă̆ uygulamalarından biri Swarm uygulamasıdır. Bu sebeple, araştırma Swarm kullanıcıları üzerine gerçekleştirilmiştir. Çalışmada, Swarm kullanım alışkanlıklarının ve Swarm kullanıcılarının davranışlarına etki eden faktörlerin ortaya konması amaçlanmıştır. Ortaya çıkan sonuçlara göre Swarm kullanma alı̧kanlıkları; kullanıcıların yer bildirimi yapma sıklı̆̆ı ve kullanicılar tarafindan yer bildirimi yapılan mekanlar olarak stralanmaktadır. Swarm kullanma davranışları ise dört faktör altında toplanmaktadır. Bunlar; kullanım kolaylı̆̆ı, elde edilen faydalar, eğlence ve hedonik değer ile sosyal etki ve bağlanmadır. Ayrıca, Swarm kullanım alışkanlıklarının Swarm kullanma davranışlarını oluşturan tüm faktörlere genel olarak yüksek derecede veya güçlü bir şekilde etkide bulunduğu tespit edilmiştir.
\end{abstract}

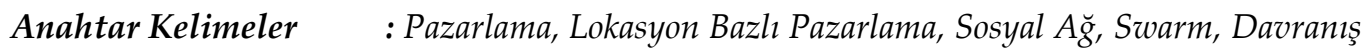

\section{Using Social Network Applications For Location Based Marketing: A Research On Swarm Users}

\begin{abstract}
Depending on the developing and changing digital technology, marketing strategies take place themselves in the digital platform. As internet began to be used widely by mobile phones, one of the concepts that is added in marketing literature is called location based marketing. In this study, the use of social networking applications in terms of location based marketing has been examined. While social networking applications like Foursquare, Google Plus, Gypsii, Plazes and Facebook, Swarm is one of the most popular social networking applications in recent times. For this reason, the research was conducted on Swarm users. In the study, it was aimed to reveal the Swarm usage habits and the factors affecting Swarm use behaviours. According to results; Swarm usage habits are listed as the frequency of place declarations and the places where place notifications are made by users. Swarm use behaviours are grouped under four factors which are ease of use, benefits obtained, entertainment and hedonic value, social impact and connectivity. It has also been found that Swarm usage habits generally have a high or strong effect on all of the factors which is about Swarm use behaviours.
\end{abstract}

Keywords : : Marketing, Location Based Marketing, Social Network, Swarm, Behaviour 


\section{Giriş}

Mobil cihazlar ve Küresel Konumlandırma Sistemi'nde (GPS-Global Positioning System) yaşanan en son teknolojik gelişmeler, lokasyon bazlı sosyal ağların şekillenmesine ve gelişimine ön ayak olmaktadır (Karimi \& Yektaei, 2015: 55). Bu sayede, işletmeler mobil uygulamaları kullanarak etki alanlarında yer alan potansiyel müşterilere kolaylıkla ve kısa sürede ulaşabilmektedir. Potansiyel müşteriler mobil uygulamalar sayesinde bulundukları yerleri belirtebilmekte veya cep telefonu operatörleri ile işbirliğine giden işletmeler satın alma noktalarında müşterilere örneğin SMS (Short Message Service, Kısa Mesaj Servisi) ile ulaşabilmektedir. Bu sayede uygulanan pazarlamaya ise lokasyon bazlı pazarlama adı verilmektedir (Çiftçi, 2016).

\section{Literatür Analizi}

Bu kısımda lokasyon bazlı pazarlama ile ilgili temel konulara yer verilmiştir. Alt başlıklar sırasıyla; lokasyon bazlı pazarlama kavramı, lokasyon bazlı sosyal ağ uygulamaları ve lokasyon bazlı pazarlama ile ilgili uygulama örnekleri şeklinde sıralanmaktadır.

\subsection{Lokasyon Bazlı Pazarlama Kavramı}

Lokasyon kelime anlamı itibariyle yer, bölge, coğrafya gibi anlamlarda kullanılmaktadır. İnternet ortamında ise sunucuların nerede bulunduklarını belirten bir kavramdır. Gelişen mobil teknolojiler ve uygulamalar sayesinde müşteriler internette sürekli aktif olabilmekte ve bulundukları lokasyonları, lokasyon bazlı sosyal ağlara ait uygulamalar ile paylaşabilmektedir (Altindal, 2013: 1090).

Lokasyon bazlı sosyal ağlara ait uygulamalar pazarlama alanında lokasyon bazlı pazarlama anlayışının ortaya çıkmasına neden olmuştur. Lokasyon bazlı pazarlama, doğru zaman ve yerde potansiyel müşteri adayını tanıyıp, ona ulaşabilmeyi ve onu bir müşteri adayına çevirebilmeyi olanaklı kılmaktadır (Gündebahar \& Kuş-Khalilov, 2013: 457).

MMA (Mobile Marketing Association) lokasyon bazlı pazarlamayı, pazarlama mesajı iletmek ya da geliştirmek için coğrafi konum kullanımını içeren herhangi bir uygulama, servis veya kampanya şeklinde tanımlamaktadır (Mobile Marketing Association, 2011: 4).

Kısacası; lokasyon bazlı pazarlamayı, müşterilerin bulunduğu konuma ya da yere göre içerik gösterimidir şeklinde tanımlamak mümkündür. Artık müşteriler, birçok Alışveriş Merkezinde (AVM) veya satın alma noktasında dolaşırken, cep telefonlarına gelen SMS ile ikramlar, indirimler veya başka fırsatlar hakkında bilgilendirme imkanlarından yararlanabilmektedirler. (Uğurlu, 2016: 217).

Lokasyon bazlı pazarlama kavramını daha iyi anlamak için yukarıda yapılan tanımlarla sınırlı kalınmamalıdır. Bunun için lokasyon bazlı pazarlamanın, pazarlama karması içindeki yerine bakmak gerekmektedir. Şekil 1'de lokasyon bazlı pazarlamanın, pazarlama karması içindeki yeri gösterilmektedir. 


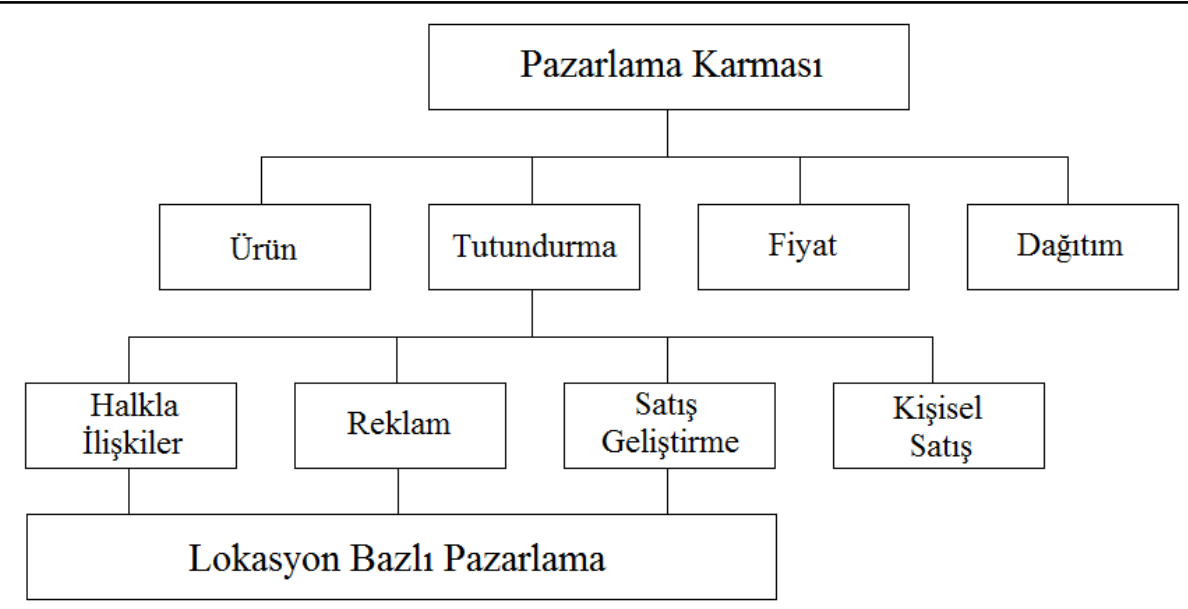

Şekil 1. Lokasyon Bazlı Pazarlamanın Pazarlama Karması İçindeki Yeri

Kaynak: Buczkowski, A. (2012). Location based marketing: The academic framework. https://run.unl.pt/bitstream/10362/8314/1/TGEO0070.pdf, Erişim Tarihi: 15.05.2017, 25.

Şekil 1'de görüldüğü üzere; lokasyon bazlı pazarlama, pazarlama karması içindeki tutundurma karması elemanlarının bileşiminden (kişisel satış hariç) oluşmaktadır. Lokasyon bazlı pazarlama mobil, sosyal medya ve konumlandırma teknolojilerinin integrasyonu ile pazarlama sürecinin her basamağına değer katmaktadır (Buczkowski, 2012: 25).

\subsection{Lokasyon Bazlı Sosyal Ă̆ Uygulamaları}

Lokasyon bazlı sosyal ağ uygulamalarının pek çok farklı türü vardır. Genel olarak dünya çapında en çok kullanılanlar; Foursquare, Google Plus, Gypsii, Plazes ve Facebook olarak sıralanabilir. Foursquare, kullanıcıların ne kadar sıklıkta dışarı çıktıklarına, ziyaret ettikleri yerlerin sayısına ve ziyaret ettikleri yerlerde beraber oldukları veya karşılaştıkları arkadaş sayılarına dayanan, oyun bazlı bir platform olarak değerlendirildiğinde ise kullanıcıların yaptıkları yer bildirimlerinden onlara puan kazandıran bir lokasyon bazlı sosyal ağ uygulamasıdır. Google Plus, kullanıcılara arkadaşlarının harita üzerinde nerede olduklarını görmelerine ve gizlilik ayarlarının değiştirebilmesi sayesinde bulundukları lokasyonu nasıl ve kiminle paylaşacaklarını kontrol etmelerine izin veren bir uygulamadır. Gypsii, lokasyon bazlı bir sosyal ağ olarak, kullanıcıların nerelerde neler yaptıklarına dair fotoğraf, video ve diğer bilgileri yüklemelerine imkan vermektedir. Plazes, lokasyon bazlı topluluklara odaklanan, bireylerin yapacakları aktiviteleri bir takvime doldurmasını gerektiren ve zamana dayalı olarak harita üzerinde nerede olduklarını eşleştiren bir uygulamadır. Facebook ise mobil cihazlar için geliştirdiği yeni uygulama ile kullanıcılarını, arkadaşlarının halihazırda nerede olduklarına ve ne yaptıklarına dair gerçek zamanlı olarak uyarabilmektedir. Örneğin; bir kullanıcı yer bildirimi yaptığı anda arkadaşlarına otomatik olarak bu iletilmektedir (Gana \& Thomas, 2016: 391).

Yukarıda bahsedilenlerin dışında Instagram, SnapChat, YouTube gibi fotoğraf, video gibi görsel ve işitsel paylaşıma olanak veren, Facebook haricinde Twitter, LinkenIn ve My Space gibi kullanıcıların kendi profillerini oluşturmalarına, yönetmelerine ve diğer kullanıcılarla iletişim halinde olmalarına imkan veren sosyal ağlar da mevcuttur (Bakır \& Aydoğan, 2015: 197). 
Bahsedilen sosyal ağlara eklenen en son ve en popüler lokasyon bazlı uygulamalardan biri Foursquare uygulamasının 2014 yılı içerisinde ikiye bölünmesi ile birlikte ortaya çıkan, yer bildirimi fonksiyonuna sahip "Swarm" adlı uygulamadır. Bu uygulamayı kullananlar arzu ederlerse arkadaşlarının yaptıkları yer bildirimlerini de beğenebilmekte ve yorum yapabilmektedir. Swarm uygulaması ile gelen en yeni özellik ise kullanıcı listesinde yer alanları bulundukları mesafeye göre kategorilere ayırıp, göstermesidir. Oysa, Foursquare sadece yeni mekanlar keşfetme ve keşfedilen mekanlarla ilgili kullanıcıların verdikleri bilgiler üzerine odaklanmıştır (Aydın, 2015: 86). Dolayısıyla, Foursquare kullanıcıların ilgi duydukları ya da yapacakları yer bildirimlerini keşfetmesine imkan sağlamaktadır (Battallar \& Cömert, 2015: 41).

\subsection{Lokasyon Bazlı Pazarlama İle İlgili Uygulama Örnekleri}

Lokasyon bazlı pazarlama, literatürde kendine yeni yer bulmasına rağmen işletmeler tarafından uygulamada tercih edilmektedir. Bu kısımda, lokasyon bazlı pazarlama ile ilgili yapılan kampanyalara ve uygulamalardan örneklere yer verilmiştir.

Guatemalalı Meat Pack adlı bir ayakkabı mağazası başarılı bir mobil uygulama örneğine imza atmıştır. Müşteri rakip bir işletmenin mağazasına girdiğinde uygulama aktif hale gelerek, müşteriye en yakındaki Meat pack mağazasında \%99 oranında bir indirim sunmuştur. Müşteri mağazaya ulaşana kadar uygulama aktif halde tutulmasına rağmen her geçen saniye indirim oranı uygulama tarafından düşürülmeye devam etmiştir. Kayda geçen kazanılmış en yüksek indirim oranı \%89 olmuştur (EticaretMag, 2013).

Peru'da bulunan Cencosud Bankası yeni yılda bir kampanya düzenleyerek Noel Baba hayalini yenilikçi yollardan gerçeğe dönüştürmeye karar vermiştir. Banka öncelikle Google Maps yardımıyla şubelerinin koordinatlarını çıkarmıştır. Sonrasında bu koordinatlara bağlı olarak araştırmaya geçen banka, Swarm uygulamasına kayıtlı olan 83 şubesinin yakınındaki evlerin koordinatlarını tespit etmiştir. Noel'den bir gece önce Noel Baba Swarm uygulaması ile koordinatları tespit edilen evlere gidilerek "Sonunda senin evine de geldim, hediyeni en yakın Cencosud şubesinden alabilirsin!" yazan bir mesaj bırakılmıştır. Bu kampanya sayesinde banka, Swarm kullananların ana sayfalarında yer almış ve hedef kitlenin bankayı ziyaret etmesi için etkili bir yol izleyerek, neredeyse nokta atışı yapmıştır (Reklamcılık ve Marka İletişimi Platformu, 2015).

Moskova merkezli online bir gazete olan The Village ücretsiz bir uygulama (Douche Parking) geliştirerek bir kampanya düzenlemiştir. Kampanya kapsamında sokaklarda uygunsuz park eden araçların resimleri ve plakaları sosyal ağlar üzerinden paylaşılmış ve araç sahipleri park etme konusunda daha duyarlı olmaya davet edilmiştir (EticaretMag, 2013).

2011 ylında Vodafone ve Caffé Nero birlikte bir kampanya düzenlemişlerdir. Caffé Nero mağazalarının önünden geçen Vodafone kullanıcılarına SMS ile özel bir teklif gönderilmiştir. Bu teklif sayesinde Vodafone kullanıcıları hem ikram edilen kahveleri içmişler hem de arkadaşlarına kahve hediye etme imkanı yakalamışlardır (Gündebahar \& Kuş-Khalilov, 2013: 457). 
2012 yılının en iyi lokasyon bazlı pazarlamalarından birine McDonald's imza atmıştır. Gece geç saatlere kadar açık kalan şubelerini müşterilerine duyurmuş ve kampanya esnasında işletmenin mobil uygulaması 530.000 defa ziyaret edilmiştir (EticaretMag, 2013).

Toyota'nın çocuklar için geliştirdiği ve arabanın GPS sistemiyle entegre çalışan bir uygulama, arabanın gittiği güzergahı telefon üzerinde çocuklara bir oyun olarak sunmuş ve bu oyun ile çocuklar arabayı kontrol edebilmişlerdir. Ayrıca çocuklar oyun sayesinde puan toplayabilmiş, sanal araba üzerinde değişiklik yapabilmiş ve bunları arkadaşları ile paylaşabilmişlerdir. Bu uygulama Nisan 2012'de 100.000'den fazla kişi tarafından indirilmiştir (EticaretMag, 2013).

Websture Mobil ise Swarm üzerinden bir kampanya düzenlemiştir. Firma bir araba ile dolaşarak Swarm üzerinden yer bildirimi yapmış ve orada 15 dakika kalma garantisi vermiştir. Bu süre içinde arabanın bulunduğu noktaya ya da yakın konumlara gelen müşteriler, Mobil SEO (Search Engine Optimization) uzmanı ile görüşme fırsatı bulabilmişlerdir. Müşteriler hem sorularına yanıt alabilmişler hem de indirim kuponlarına veya ücretsiz kitap ve promosyonlara sahip olabilmişlerdir (Özkömürcü, 2016).

\section{YÖNTEM}

$\mathrm{Bu}$ kısımda araştırmanın ön çalışmaları, amacı, kapsamı ve kısıtları, araştırmanın değişkenleri, araştırmanın modeli ve hipotezleri ile örnekleme planı üzerinde durulmuştur.

\subsection{Araştırmanın Ön Çalışmaları}

Araştırmada, Swarm uygulamasını kullananların davranışlarına etki eden değişkenlerin neler olduğunu belirlemek amacıyla odak grup görüşmelerinden, literatürde yapılmış ilgili çalışmalardan ve konunun uzmanı akademisyenlerin ve sektör profesyonellerinin görüşlerinden yararlanılmıştır. Ayrıca, araştırma öncesi yapılan ön çalışmalarda, Swarm kullanıcılarının uygulamayı kullanım alışkanlıklarını belirlemek amacıyla sorulması gereken sorular üzerinde de durulmuştur.

\subsection{Araștırmanın Amacı, Kapsamı ve Kısıtları}

Araştırmanın temel amacı, Swarm kullanım alışkanlıklarının ve Swarm kullanıcılarının davranışlarına etki eden faktörlerin ortaya konmasıdır. Ayrıca, araştırmaya katılanların sosyodemografik özelliklerinin belirlenmesi ve bu özellikler arasında Swarm kullanıcılarının davranışlarını oluşturan faktörler açısından farklılık olup olmadığının belirlenmesi amaçlanmaktadır.

Araştırma, İstanbul'da en az 1 yıldır Swarm uygulamasını kullananlar ile gerçekleştirilmiştir. Zaman ve maliyet açısından kısıtları da göz önünde bulundurarak, araştırmada bilgi toplamak için hazırlanan anket, 1 Haziran - 20 Haziran 2017 tarihleri arasında ilgili katılımcılar tarafından doldurulmuştur. 


\subsection{Araştırmanın Değişkenleri}

Araştırmanın değişkenleri üç ana bölüme ayrılmıştır. Bunlar; Swarm kullanıcılarına ait sosyodemografik özellikler, Swarm kullanım alışkanlıkları ve Swarm kullanımı ile ilgili davranışlardır. Tablo 1'de araştırmada yer alan değişkenlere ait bilgilere ve bilgi kaynaklarına yer verilmiştir.

Tablo 1. Araştırmanın Değişkenleri

\begin{tabular}{|c|c|c|}
\hline \multicolumn{2}{|c|}{ Sosyo-Demografik Özellikler } & $\begin{array}{l}4 \text { Değişken (Cinsiyet, Yaş, Gelir } \\
\text { Durumu ve Eğitim Durumu) }\end{array}$ \\
\hline $\begin{array}{l}\text { Swarm } \\
\text { Alışkanlıkları }\end{array}$ & Kullanım & $\begin{array}{l}2 \text { Değişken (Odak grup görüşmeleri, } \\
\text { akademisyen ve profesyonellerin } \\
\text { görüşleri) }\end{array}$ \\
\hline $\begin{array}{l}\text { Swarm } \\
\text { Davranışları }\end{array}$ & Kullanma & $\begin{array}{l}29 \text { Değişken (Odak grup görüşmeleri, } \\
\text { akademisyen ve profesyonellerin } \\
\text { görüşleri, Batra \& Ahtola (1990), Voss, } \\
\text { Spangenberg \& Grohmann (2003), } \\
\text { Daştan (2015), Bakır \& Aydoğan } \\
\text { (2015), Bekar \& Özçetin (2015), Tatar \& } \\
\text { Erdoğmuş (2016)) }\end{array}$ \\
\hline
\end{tabular}

Swarm kullanım alışkanlıkları ile ilgili değiş̧kenler (Odak grup görüşmeleri, akademisyen ve profesyonellerin görüşleri):

- SKA1 - Swarm kullanarak yer bildirimi yapma sıklığ1

- SKA2 - En çok ne tip mekanlarda yer bildirimi yapıldığ1

Swarm kullanma davranışları ile ilgili değişkenler (Odak grup görüşmeleri, akademisyen ve profesyonellerin görüşleri, Batra \& Ahtola (1990, s. 167), Voss vd. (2003, s. 312) Daştan (2015, s. 42-43), Bakır \& Aydoğan (2015, s. 201), Bekar \& Özçetin (2015, s. 419), Tatar \& Erdoğmuş (2016, s. 72)):

- SKD1 - Swarm uygulamasina kolaylikla üye olmak

- SKD2 - Swarm uygulamasının özelliklerini rahatlıkla öğrenmek

- SKD3 - Swarm uygulamasının özelliklerini zorluk çekmeden kullanmak

- SKD4 - Swarm uygulamasını eğlenceli bulmak

- SKD5 - Eğlenilen mekanlarda yer bildirimi yapmak

- SKD6 - Yer bildirimi yapmayı eğlenceli bulmak

- SKD7 - Popüler mekanlarda yer bildirimi yaparak başkaları tarafından fark edilmek

- SKD8 - Yer bildirimi yaparak arkadaşlar arasında popülerliği artırmak

- SKD9 - Yer bildirimi yapılan mekanlar ile yaşam tarzını yansıtmak

- SKD10 - Sevilen mekanlarda yer bildirimi yaparak mutlu olmak

- SKD11 - Vakit geçirmek amaçli yer bildirimi yapmak

- SKD12 - Gidilen mekanda online olup orada bulunan diğer insanları takip etmekten hoşlanmak 
- SKD13 - Arkadaşları takip etmek amacıyla Swarm uygulamasını kullanmak

- SKD14 - Ziyaret edilen yerleri arkadaşlarla paylaşmak amacıyla Swarm uygulamasını kullanmak

- SKD15 - Ziyaret edilen mekanlar hakkında arkadaşların görüşlerini almak amacıyla Swarm uygulamasını kullanmak

- SKD16 - Yer bildirimi yaparak kimlerle birlikte olunduğu hakkında arkadaşlara bilgi vermek

- SKD17 - Popüler mekanlarda yer bildirimi yaparak kendini güncel hissetmek

- SKD18 - Farklı mekanlarda yer bildirimi yaparak orijinal bir kişiliğe sahip olunduğunu yansitmak

- SKD19 - Yer bildirimi yaparak mekan zevkini ortaya koymak

- SKD20 - Yer bildirimi yapılan mekanlarla kişiliğini yansıtmak

- SKD21 - Yer bildirimi yaparak saygınlık/prestij kazanmak

- SKD22 - Yer bildirimi yaparak stres atmak

- SKD23 - Sikıcı bir yerde yer bildirimi yaparak sıkıntıdan kurtulmak

- SKD24 - Fikirlerine değer verilen arkadaşlar Swarm uygulamasının kullanılmasını önerdiği için kullanmak

- SKD25 - Fikirlerine değer verilen arkadaşlar Swarm uygulaması kullandığı için kullanmak

- SKD26 - Arkadaşlar Swarm uygulamasını iletişim amaçlı kullandığı için kullanmak

- SKD27 - Arkadaşların çoğu Swarm uygulaması kullandığı için kullanmak

- SKD28 - Yer bildirimi yaparak etiket kazanmak

- SKD29 - Aynı mekanda yer bildirimi yaparak mayor olmak

\subsection{Araştırmanın Modeli ve Hipotezleri}

Araştırmanın ön çalışmaları ve ortaya konan değişkenler çerçevesinde belirlenen araştırma modeli Şekil 2'de görülmektedir. Modelde yer alan unsurlar; araştırmaya katılan Swarm kullanıcılarının sosyo-demografik özellikleri, Swarm kullanım alışkanlıkları ve Swarm kullanma davranışlarını oluşturan faktörler şeklinde ifade edilmiştir.

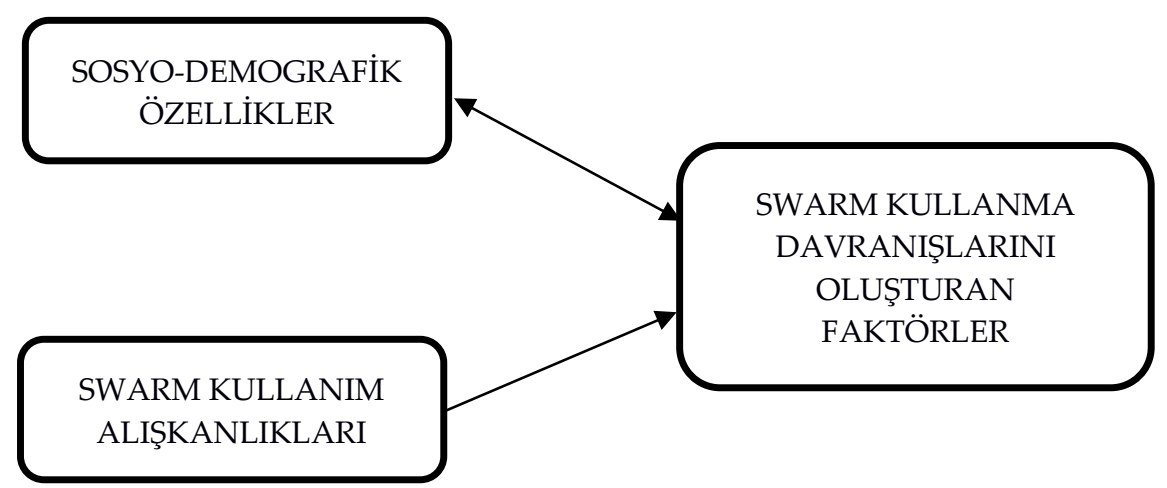

Şekil 2. Araştırmanın Modeli

Şekil 2'de yer alan araştırmanın modeline bağlı olarak test edilecek hipotezleri ise şu şekilde sıralamak mümkündür: 
Birinci hipotez:

- H10: Swarm kullanma davranışlarını oluşturan faktörler açısından kullanıcıların sosyodemografik özellikleri arasında $\alpha=0,05$ anlamlılık düzeyinde istatistiki olarak anlamlı bir fark bulunmamaktadır.

- H11: Swarm kullanma davranışlarını oluşturan faktörler açısından kullanıcıların sosyodemografik özellikleri arasında $\alpha=0,05$ anlamlılık düzeyinde istatistiki olarak anlamlı bir fark bulunmaktadır.

Birinci hipoteze bağlı alt hipotezler ise şu şekilde ifade edilebilir:

- Hıa: Swarm kullanma davranışlarını oluşturan faktörler açısından kullanıcıların cinsiyetleri arasında $\alpha=0,05$ anlamlılık düzeyinde istatistiki olarak anlamlı bir fark bulunmamaktadir.

- Hıa1: Swarm kullanma davranışlarını oluşturan faktörler açısından kullanıcıların cinsiyetleri arasında $\alpha=0,05$ anlamlılık düzeyinde istatistiki olarak anlamlı bir fark bulunmaktadir.

- Hıbo: Swarm kullanma davranışlarını oluşturan faktörler açısından kullanıcıların yaşları arasında $\alpha=0,05$ anlamlılık düzeyinde istatistiki olarak anlamlı bir fark bulunmamaktadır.

- Hıb: Swarm kullanma davranışlarını oluşturan faktörler açısından kullanıcıların yaşları arasında $\alpha=0,05$ anlamlılık düzeyinde istatistiki olarak anlamlı bir fark bulunmaktadır.

- Hıco: Swarm kullanma davranışlarını oluşturan faktörler açısından kullanıcıların gelir durumları arasında $\alpha=0,05$ anlamlılık düzeyinde istatistiki olarak anlamlı bir fark bulunmamaktadır.

- Hıc1: Swarm kullanma davranışlarını oluşturan faktörler açısından kullanıcıların gelir durumları arasında $\alpha=0,05$ anlamlılık düzeyinde istatistiki olarak anlamlı bir fark bulunmaktadır.

- H1do: Swarm kullanma davranışlarını oluşturan faktörler açısından kullanıcıların eğitim durumları arasında $\alpha=0,05$ anlamlılık düzeyinde istatistiki olarak anlamlı bir fark bulunmamaktadir.

- Hıd: Swarm kullanma davranışlarını oluşturan faktörler açısından kullanıcıların eğitim durumları arasında $\alpha=0,05$ anlamlılık düzeyinde istatistiki olarak anlamlı bir fark bulunmaktadir.

İkinci hipotez:

- $\mathrm{H}_{20}$ : Swarm kullanım alışkanlıkları Swarm kullanma davranışını oluşturan faktörler üzerine $\alpha=0,05$ anlamlılık düzeyinde istatistiki olarak etkide bulunmamaktadır.

- $\mathrm{H}_{21}$ : Swarm kullanım alışkanlıkları Swarm kullanma davranışını oluşturan faktörler üzerine $\alpha=0,05$ anlamlılık düzeyinde istatistiki olarak etkide bulunmaktadır. 


\section{5. Örnekleme Planı}

Araştırmanın anakütlesini en az 1 yıldır Swarm uygulamasını kullananlar oluşturmaktadır. Ancak zaman ve maliyet açısından kısıtlamalar göz önünde bulundurulduğunda araştırma İstanbul'da, Avcılar-Beylikdüzü bölgesindeki alışveriş merkezlerinde gerçekleştirilmiştir. Anakütlede standart sapma ve varyansların bilinmesi pek çok zaman olanak dahilinde olmadığından tahmin edilmeleri gerekmektedir. Tahminleri yaparken oranlar üzerinden yapmak çok daha kolay olacaktır. Oranlar hakkında hiçbir bilgi sahibi olunmasa dahi П(1-П)'nin en yüksek olduğu $(0,5 \times 0,5=0,25)$ değeri esas alınabilir. Tüm bu nedenlerden dolayı uygulamada en yaygın kullanılan örnekleme formülü şu şekilde ifade edilmektedir (Kurtuluş, 1989: 113): $n=\Pi(1-\Pi) /(e / z)^{2}$. Bu formüle göre örnek büyüklüğü, maksimum varyanslı $(0,5 \times 0,5=0,25)$ ve \%95 güven aralığı içinde $z^{\prime}$ nin aldığ 1 değer 1,96 olduğundan, seçilecek örnek büyüklüğü 384 kişi olmalıdır. Bu durumu göz önünde bulundurarak 1 Haziran - 20 Haziran 2017 tarihleri arasında 459 kişiyle anket çalışması gerçekleştirilmiştir.

\section{Araştırmanın Bulguları}

Bu kısımda sırasıyla, Swarm kullanıcılarının sosyo-demografik özelliklerine, Swarm kullanım alışkanlıklarına, Swarm kullanma davranışlarına ilişkin faktör analizine ve son olarak araştırmada yer alan hipotezlerin test edilmesine yer verilmiştir.

\subsection{Swarm Kullanıcılarının Sosyo-Demografik Özellikleri}

Araştırmaya katılan Swarm kullanıcılarının sosyo-demografik özellikleri Tablo 2'de özetlenmiştir. İncelenen sosyo-demografik özellikler; kullanıcıların cinsiyeti, yaşı, gelir durumu ve son olarak da eğitim durumu şeklinde sıralanmaktadır.

Tablo 2. Swarm Kullanıcılarının Sosyo-Demografik Özellikleri

\begin{tabular}{|c|c|c|c|}
\hline & & Frekans & Yüzde \\
\hline \multirow{2}{*}{ Cinsiyet } & Kadın & 263 & 57,3 \\
\hline & Erkek & 196 & 42,7 \\
\hline \multirow{5}{*}{ Yaş } & 18 ve altı & 171 & 37,3 \\
\hline & $19-25$ & 180 & 39,2 \\
\hline & $26-35$ & 68 & 14,8 \\
\hline & $36-45$ & 34 & 7,4 \\
\hline & 46 ve üzeri & 6 & 1,3 \\
\hline \multirow{4}{*}{ Gelir Durumu } & $0-1500 \mathrm{TL}$ & 216 & 47,1 \\
\hline & $1501-2500 \mathrm{TL}$ & 175 & 38,1 \\
\hline & 2501-4000 TL & 64 & 13,9 \\
\hline & 4001 TL ve üstü & 4 & 0,9 \\
\hline \multirow{5}{*}{ Eğitim Durumu } & Okuryazar & 6 & 1,3 \\
\hline & İlköğretim & 7 & 1,5 \\
\hline & Lise & 199 & 43,4 \\
\hline & Önlisans (2 yıllık) ve Lisans (4 Yıllık) & 223 & 48,6 \\
\hline & Yüksek Lisans ve Doktora & 24 & 5,2 \\
\hline
\end{tabular}

Tablo 2'de görüldüğü üzere Swarm kullanıcılarının \%57,3'ü (263 kişi) kadın ve \%42,7'si (196 kişi) erkeklerden oluşmaktadır. Yaş bakımından dağılım; \%37,3 (171 kişi) 18 yaş ve altı, \%39,2 (180 kişi) 19 - 25 yaş arası, \%14,8 (68 kişi) 26 - 35 yaş arası, \%7,4 (34 kişi) 36-45 yaş arası ve \%1,3 (6 kişi) 46 yaş ve üzeri şeklindedir. Gelir durumu açısından Swarm kullanıcılarının, \%47,1'inin (216 kişi) 0 - 
1500 TL arası, \%38,1'inin (175 kişi) 1501 - 2500 TL arası, \%13,9'unun (64 kişi) 2501 - 4000 TL arası ve \%0,9'unun 4001 TL ve üstü gelire sahip olduğu görülmektedir. Eğitim durumu açısından ise \%1,3'ü (6 kişi) okuryazar, \%1,5'i (7 kişi) ilköğretim, \%43,4'ü (199 kişi) lise, \%48,6'sı (223 kişi) önlisans ve lisans ve son olarak \%5,2 (24 kişi) yüksek lisans ve doktora mezunudur.

\subsection{Swarm Kullanım Alışkanlıkları}

Araştırmaya dahil olan Swarm kullanıcılarının, Swarm kullanım alışkanlıkları ile ilgili bilgiler Tablo 3 ve Tablo 4'te görülmektedir. Tablo 3'te Swarm kullanma sıklı̆̆1 ile yer bildirimi yapma sıklığı ile ilgili bilgiler yer alırken, Tablo 4 'te en çok hangi tip mekanlarda yer bildirimi yapıldığı ile ilgili bilgiler yer almaktadır.

Tablo 3. Swarm Kullanarak Yer Bildirimi Yapma Sıklığ

\begin{tabular}{|c|c|c|}
\hline \multirow{2}{*}{} & \multicolumn{2}{|c|}{ Swarm Kullanma Sıklı̆̆1 } \\
\cline { 2 - 3 } $\begin{array}{c}\text { Her gün } \\
\text { defalarca }\end{array}$ & Frekans & Yüzde \\
\hline Haftada 3-5 gün & 256 & 55,8 \\
\hline Haftada 1-2 gün & 58 & 19,2 \\
\hline Ayda birkaç kez & 41 & 12,4 \\
\hline Y1lda birkaç kez & 17 & 8,9 \\
\hline Toplam & 459 & 3,7 \\
\hline
\end{tabular}

Tablo 3'te Swarm kullanıcilarının yer bildirimi yapma sıklığı ifade edilmektedir. Buna göre kullanıcıların \%55,8'i (256 kişi) her gün defalarca, \%19,2'si (88 kişi) haftada 3-5 gün, \%12,4'ü (57 kişi) haftada 1-2 gün, \%8,9'u (41 kişi) ayda birkaç kez ve son olarak \%3,7'si (17 kişi) yılda birkaç kez Swarm uygulamasında yer bildirimi yapmaktadır.

Tablo 4. En Çok Yer Bildirimi Yapılan Mekan Dağılımı

\begin{tabular}{|c|c|c|}
\hline & \multicolumn{2}{|c|}{$\begin{array}{c}\text { En Çok Yer Bildirimi Yapılan } \\
\text { Mekanlar }\end{array}$} \\
\hline Gidilen kafe/restaurant/bar/otel gibi mekanlar & Frekans & Yüzde \\
\hline Her gün gidilen okul/işyeri mekanlar & 285 & 62,1 \\
\hline Gidilen sinema/tiyatro/müze/sergi gibi mekanlar & 71 & 15,5 \\
\hline Bulunulan şehir/semt/yol/havaalanı/ otogar gibi mekanlar & 39 & 8,5 \\
\hline İkamet edilen yerde & 34 & 7,4 \\
\hline Diğer (Her gidilen yer, yukarıdakilerin dişında vs.) & 12 & 2,6 \\
\hline
\end{tabular}

Tablo 4'te Swarm kullanıcılarının en çok hangi mekanlarda yer bildirimi yaptıkları görülmektedir. Buna göre kullanıcıların \%62,1'i (285 kişi) gidilen kafe/restaurant/bar/otel gibi mekanlarda, \%15,5'i (71 kişi) her gün gidilen okul/işyeri mekanlarda, \%8,5'i (39 kişi) gidilen sinema/tiyatro/müze/sergi gibi mekanlarda, \%7,4’ü (34 kişi) bulunulan şehir/semt/yol/havaalanı/ otogar gibi mekanlarda, 
\%2,6 (12 kişi) ikamet edilen yerde ve son olarak \%3,9’u (18 kişi) diğer mekanlarda yer bildirimi yaptıklarını belirtmişlerdir.

\subsection{Swarm Kullanma Davranışlarına İlişkin Faktör Analizi}

Swarm kullanıcılarının, Swarm uygulamasını kullanma davranışlarının hangi faktörler altında toplandığını belirlemek amacıyla faktör analizi yapılmıştır. Davranışları ölçmek amacıyla kullanılan ölçeğin faktör analizine uygunluğunu belirlemek için öncelikle KMO ve Bartlett testi uygulanmış ve sonuçları Tablo 5'te paylaşılmıştır.

Tablo 5. Swarm Kullanma Davranışları Ölçeğine İlişkin KMO ve Bartlett Tablosu

\begin{tabular}{|l|l|l|}
\hline \multicolumn{2}{|l|}{ Kaiser-Meyer-Olkin Measure (Örnek Yeterliliğinin Ölçümü) } & 0,93 \\
\hline \multirow{3}{*}{ Bartlett Küresellik Testi } & Yaklaşık Ki-Kare & 4215,58 \\
\cline { 2 - 3 } & Df (Serbestlik Derecesi) & 498 \\
\cline { 2 - 3 } & Anlamlılık $(\alpha)$ & 0,00 \\
\hline
\end{tabular}

Tablo 5'e göre KMO değeri 0,93 elde edilmiş, araştırmadaki örneklemin faktör analizi yapmak için yeterli olduğu sonucuna ulaşılmıştır. Bartlett Küresellik Testine göre Ki-Kare değeri 4215,58 ve $\alpha=$ 0,00 'dır. Ortaya çıkan sonuçlar, faktör analizinin uygulanabileceğini göstermektedir. Faktör analizi ve ortaya çıkan faktörlerin güvenilirlik analizi sonuçları ise Tablo $6^{\prime}$ da özetlenmiştir.

Tablo 6. Swarm Kullanım Davranışlarına Ait Faktörler, Güvenilirlikleri ve Faktör Analizi Sonuçları

\begin{tabular}{lcc}
\hline Faktörler ve Değişkenler & $\begin{array}{c}\text { Faktör } \\
\text { Yükleri }\end{array}$ & $\begin{array}{c}\text { Alpha } \\
\text { Katsayısı }\end{array}$ \\
\hline Faktör 1 - Kullanım Kolaylığı & 0,781 \\
SKD1 - Swarm uygulamasına kolaylıkla üye olmak &, 651 & \\
SKD2 - Swarm uygulamasının özelliklerini rahatlıkla öğrenmek &, 574 \\
SKD3 - Swarm uygulamasının özelliklerini zorluk çekmeden kullanmak &, 583 \\
Faktör 2 - Elde Edilen Faydalar & \\
SKD7 - Popüler mekanlarda yer bildirimi yaparak başkaları tarafından fark &, 678 \\
edilmek & \\
SKD8 - Yer bildirimi yaparak arkadaşlar arasında popülerliği artırmak &, 652 \\
SKD9 - Yer bildirimi yapılan mekanlar ile yaşam tarzını yansıtmak &, 733 \\
SKD17 - Popüler mekanlarda yer bildirimi yaparak kendini güncel hissetmek &, 695 \\
SKD18 - Farklı mekanlarda yer bildirimi yaparak orijinal bir kişiliğe sahip &, 682 \\
olunduğunu yansıtmak & \\
SKD19 - Yer bildirimi yaparak mekan zevkini ortaya koymak & \\
SKD20 - Yer bildirimi yapılan mekanlarla kişiliğini yansıtmak & \\
SKD21 - Yer bildirimi yaparak saygınlık/prestij kazanmak & \\
Faktör 3 -Eğlence ve Hedonik Değer & \\
SKD4 - Swarm uygulamasını eğlenceli bulmak &, 521 \\
SKD5 - Eğlenilen mekanlarda yer bildirimi yapmak &, 584 \\
SKD6 - Yer bildirimi yapmayı eğlenceli bulmak &, 758 \\
SKD10 - Sevilen mekanlarda yer bildirimi yaparak mutlu olmak &, 672 \\
SKD11 - Vakit geçirmek amaçlı yer bildirimi yapmak &, 764 \\
\hline
\end{tabular}


SKD12 - Gidilen mekanda online olup orada bulunan diğer insanları takip

, 772 etmekten hoşlanmak

SKD22 - Yer bildirimi yaparak stres atmak

SKD23 - Sıkıcı bir yerde yer bildirimi yaparak sıkıntıdan kurtulmak

SKD28 - Yer bildirimi yaparak etiket kazanmak

SKD29 - Aynı mekanda yer bildirimi yaparak mayor olmak

Faktör 4 - Sosyal Etki ve Bağlanma

SKD24 - Fikirlerine değer verilen arkadaşlar Swarm uygulamasının 0,876

,733

kullanılmasını önerdiği için kullanmak

SKD25 - Fikirlerine değer verilen arkadaşlar Swarm uygulaması kullandığı için

, 696

kullanmak

SKD26 - Arkadaşlar Swarm uygulamasını iletişim amaçlı kullandığı için

kullanmak

SKD27 - Arkadaşların çoğu Swarm uygulaması kullandığı için kullanmak

SKD14 - Ziyaret edilen yerleri arkadaşlarla paylaşmak amacıyla Swarm

uygulamasını kullanmak

SKD15 - Ziyaret edilen mekanlar hakkında arkadaşların görüşlerini almak

amacıyla Swarm uygulamasını kullanmak

SKD16 - Yer bildirimi yaparak kimlerle birlikte olunduğu hakkında arkadaşlara bilgi vermek

Çıkarım Yöntemi: Temel Bileşenler Analizi

Rotasyon Yöntemi: Varimax with Kaiser Normalization

İterasyon Sayısı: 7

Toplam Açılanan Varyans: \%63,5

Ölçeğin Güvenilirliği: \%92,3

Tablo 6'da görüldüğü üzere faktör analizi sonucunda öz değeri 1'den büyük olan 4 faktör tespit edilmiştir. Bunlar; kullanım kolaylığı, elde edilen faydalar, eğlence ve hedonik değer ile sosyal etki ve bağlanmadır. Toplam açıklanan varyans \%63,5 olarak bulunmuştur. Ölçeğin güvenilirliği ise $\% 92,3$ gibi yüksek bir değere sahiptir.

\subsection{Araştırmada Yer Alan Hipotezlerin Test Edilmesi}

Araştırmada öne sürülen hipotezlerin test edilmesi amacıyla fark analizlerinden ve regresyon analizinden faydalanılmıştır. Swarm kullanma davranışlarını ortaya koyan ölçeğin normal dağılım gösterip göstermediğine ilişkin yapılan Shapiro-Wilk testi sonucuna göre ölçeğin normal dağılım göstermediği tespit edilmiştir. Bu nedenle fark analizleri için parametrik olmayan Mann-Whitney U ve Kruskal Wallis testleri kullanılmıştır. Son olarak, Swarm kullanım alışkanlıklarının Swarm kullanma davranışlarını oluşturan faktörler üzerine etkisini incelemek amacıyla da regresyon analizinden yararlanılmıştır. 
Tablo 7. Swarm Kullanma Davranışlarını Oluşturan Faktörlerin Cinsiyete Göre Karşılaştırılması

\begin{tabular}{|c|c|c|c|c|c|}
\hline $\begin{array}{c}\text { Swarm Kullanma Davranışlarını } \\
\text { Oluşturan Faktörler }\end{array}$ & Cinsiyet & $\mathbf{N}$ & Sira Ortalaması & $\mathrm{U}$ & $\mathbf{p}$ \\
\hline \multirow{2}{*}{ Faktör 1 - Kullanım Kolaylığı } & Kadın & 263 & 198,57 & \multirow{2}{*}{223765} & \multirow{2}{*}{0,19} \\
\hline & Erkek & 196 & 255,78 & & \\
\hline \multirow{2}{*}{ Faktör 2 - Elde Edilen Faydalar } & Kadın & 263 & 191,22 & \multirow{2}{*}{232512} & \multirow[b]{2}{*}{0,24} \\
\hline & Erkek & 196 & 261,64 & & \\
\hline \multirow{2}{*}{$\begin{array}{c}\text { Faktör } 3 \text { - Eğlence ve Hedonik } \\
\text { Değer }\end{array}$} & Kadın & 263 & 253,83 & \multirow{2}{*}{229321} & \multirow[b]{2}{*}{0,44} \\
\hline & Erkek & 196 & 202,51 & & \\
\hline \multirow{2}{*}{$\begin{array}{c}\text { Faktör } 4 \text { - Sosyal Etki ve } \\
\text { Bağlanma }\end{array}$} & Kadın & 263 & 193,12 & \multirow{2}{*}{241223} & \multirow[b]{2}{*}{0,02} \\
\hline & Erkek & 196 & 262,81 & & \\
\hline
\end{tabular}

Tablo 7'de görülmekte olan Mann-Whitney U testi sonuçlarına göre Swarm kullanma davranışlarını oluşturan faktörlerden; kullanım kolaylığı, elde edilen faydalar ile eğlence ve hedonik değer, anlamlılık düzeyi (p) arzu edilen \%5'ten büyük olduğu için Swarm kullanıcılarının cinsiyetlerine göre farklılık göstermemektedir. Ancak, sosyal etki ve bağlanma, anlamlılık düzeyi (p) \%5'ten küçük olduğu için Swarm kullanıcılarının cinsiyetlerine göre farklılık göstermektedir. Cinsiyet dağılımındaki sıra ortalamasına bakıldığında ise erkeklerin sosyal etki ve bağlanma düzeylerinin kadınlara oranla daha yüksek olduğu görülmektedir. Bu durumda, Faktör 1, 2 ve 3 için $\mathrm{H}_{1 a 0}$ kabul edilirken Faktör 4 için reddedilmektedir.

Tablo 8. Swarm Kullanma Davranışını Oluşturan Faktörlerin Yaşa Göre Karşılaştırılması

\begin{tabular}{|c|c|c|c|c|c|}
\hline $\begin{array}{c}\text { Swarm Kullanma Davranışlarını } \\
\text { Oluşturan Faktörler }\end{array}$ & Yaş & $\mathbf{N}$ & Sira Ortalamasi & $X^{2}$ & $\mathrm{p}$ \\
\hline \multirow{5}{*}{ Faktör 1 - Kullanım Kolaylığ } & 18 ve altı & 171 & 298,17 & \multirow{5}{*}{212,36} & \multirow{5}{*}{0,01} \\
\hline & $19-25$ & 180 & 312,53 & & \\
\hline & $26-35$ & 68 & 250,95 & & \\
\hline & $36-45$ & 34 & 198,41 & & \\
\hline & 46 ve üzeri & 6 & 112,75 & & \\
\hline \multirow{5}{*}{ Faktör 2 - Elde Edilen Faydalar } & 18 ve altı & 171 & 303,23 & \multirow{5}{*}{219,72} & \multirow{5}{*}{0,00} \\
\hline & $19-25$ & 180 & 314,31 & & \\
\hline & $26-35$ & 68 & 267,45 & & \\
\hline & $36-45$ & 34 & 221,11 & & \\
\hline & 46 ve üzeri & 6 & 141,98 & & \\
\hline \multirow{5}{*}{ Faktör 3 - Eğlence ve Hedonik Değer } & 18 ve altı & 171 & 338,78 & \multirow{5}{*}{198,21} & \multirow{5}{*}{0,02} \\
\hline & $19-25$ & 180 & 300,91 & & \\
\hline & $26-35$ & 68 & 291,51 & & \\
\hline & $36-45$ & 34 & 225,64 & & \\
\hline & 46 ve üzeri & 6 & 136,35 & & \\
\hline \multirow{5}{*}{ Faktör 4 - Sosyal Etki ve Bağlanma } & 18 ve altı & 171 & 299,72 & \multirow{5}{*}{233,54} & \multirow{5}{*}{0,00} \\
\hline & $19-25$ & 180 & 356,15 & & \\
\hline & $26-35$ & 68 & 283,94 & & \\
\hline & $36-45$ & 34 & 225,76 & & \\
\hline & 46 ve üzeri & 6 & 103,61 & & \\
\hline
\end{tabular}


Tablo 8'de Swarm kullanma davranışlarını oluşturan faktörlerin Swarm kullanıcılarının yaşlarına göre karşılaştırılması yer almaktadır. Tüm faktörlerin, anlamlılık düzeyleri (p) istenilen \%5 değerinden küçük olduğu için yaşa göre farklılık gösterdikleri tespit edilmiştir. Bu durumda tüm faktörler açısından $\mathrm{H}_{1 b 0}$ reddedilmektedir. Faktörler açısından yaşa göre sıra ortalamalarına bakıldığında; kullanım kolaylığı, elde edilen faydalar ile sosyal etki ve bağlanma açısından 19-25 yaş aralığının, eğlence ve hedonik değer açısından ise 18 ve altı yaş aralığının diğer yaş aralıklarına göre daha yüksek düzeylerde olduğu görülmektedir.

Tablo 9. Swarm Kullanma Davranışını Oluşturan Faktörlerin Gelir Durumuna Göre Karşılaştırılması

\begin{tabular}{|c|c|c|c|c|c|}
\hline $\begin{array}{c}\text { Swarm Kullanma Davranışlarını } \\
\text { Oluşturan Faktörler }\end{array}$ & Gelir Durumu & $\mathbf{N}$ & $\begin{array}{c}\text { Sira } \\
\text { Ortalamasi }\end{array}$ & $\mathbf{X}^{2}$ & $\mathbf{p}$ \\
\hline \multirow{4}{*}{ Faktör 1 - Kullanım Kolaylığı } & $0-1500 \mathrm{TL}$ & 216 & 292,23 & \multirow{4}{*}{5,34} & \multirow{4}{*}{0,55} \\
\hline & $1501-2500 \mathrm{TL}$ & 175 & 278,61 & & \\
\hline & 2501-4000 TL & 64 & 198,94 & & \\
\hline & 4001 TL ve üstü & 4 & 201,53 & & \\
\hline \multirow{4}{*}{ Faktör 2 - Elde Edilen Faydalar } & $0-1500 \mathrm{TL}$ & 216 & 283,21 & \multirow{4}{*}{4,94} & \multirow{4}{*}{0,59} \\
\hline & $1501-2500 \mathrm{TL}$ & 175 & 277,09 & & \\
\hline & 2501-4000 TL & 64 & 226,48 & & \\
\hline & 4001 TL ve üstü & 4 & 216,79 & & \\
\hline \multirow{4}{*}{$\begin{array}{c}\text { Faktör } 3 \text { - Eğlence ve Hedonik } \\
\text { Değer }\end{array}$} & $0-1500 \mathrm{TL}$ & 216 & 288,79 & \multirow{4}{*}{4,43} & \multirow{4}{*}{0,71} \\
\hline & $1501-2500 \mathrm{TL}$ & 175 & 256,02 & & \\
\hline & $2501-4000 \mathrm{TL}$ & 64 & 230,17 & & \\
\hline & 4001 TL ve üstü & 4 & 211,01 & & \\
\hline \multirow{4}{*}{$\begin{array}{c}\text { Faktör } 4 \text { - Sosyal Etki ve } \\
\text { Bağlanma }\end{array}$} & $0-1500 \mathrm{TL}$ & 216 & 298,81 & \multirow{4}{*}{4,73} & \multirow{4}{*}{0,64} \\
\hline & $1501-2500 \mathrm{TL}$ & 175 & 281,02 & & \\
\hline & $2501-4000 \mathrm{TL}$ & 64 & 240,84 & & \\
\hline & 4001 TL ve üstü & 4 & 241,03 & & \\
\hline
\end{tabular}

Tablo 9'da sonuçları görülen Kruskal Wallis testi sonuçlarına göre Swarm kullanma davranışlarını oluşturan tüm faktörlerin anlamlılık düzeyi (p) arzu edilen \%5 değerinden büyüktür. Dolayısıyla, Swarm kullanma davranışlarını oluşturan tüm faktörlerin gelir durumuna göre farklılık göstermediği tespit edilmiştir. Buna göre tüm faktörler açısından $\mathrm{H}_{1 c 0}$ kabul edilmektedir. 
Tablo 10. Swarm Kullanma Davranışını Oluşturan Faktörlerin Eğitim Durumuna Göre Karşılaştırılması

\begin{tabular}{|c|c|c|c|c|c|}
\hline $\begin{array}{c}\text { Swarm Kullanma Davranışlarını } \\
\text { Oluşturan Faktörler }\end{array}$ & Eğitim Durumu & $\mathbf{N}$ & $\begin{array}{c}\text { Sira } \\
\text { Ortalamasi } \\
\end{array}$ & $\mathbf{X}^{2}$ & $\mathrm{p}$ \\
\hline \multirow{5}{*}{ Faktör 1 - Kullanım Kolaylığ1 } & Okuryazar & 6 & 185,89 & \multirow{5}{*}{12,79} & \multirow{5}{*}{0,24} \\
\hline & İlköğretim & 7 & 290,25 & & \\
\hline & Lise & 199 & 302,81 & & \\
\hline & $\begin{array}{l}\text { Önlisans (2 yıllık) ve } \\
\text { Lisans (4 yıllık) }\end{array}$ & 223 & 298,92 & & \\
\hline & $\begin{array}{c}\text { Yüksek Lisans ve } \\
\text { Doktora }\end{array}$ & 24 & 278,09 & & \\
\hline \multirow{5}{*}{ Faktör 2 - Elde Edilen Faydalar } & Okuryazar & 6 & 182,16 & \multirow{5}{*}{44,81} & \multirow{5}{*}{0,00} \\
\hline & İlköğretim & 7 & 292,01 & & \\
\hline & Lise & 199 & 301,22 & & \\
\hline & $\begin{array}{l}\text { Önlisans (2 y1llık) ve } \\
\text { Lisans (4 yıllık) }\end{array}$ & 223 & 280,11 & & \\
\hline & $\begin{array}{l}\text { Yüksek Lisans ve } \\
\text { Doktora }\end{array}$ & 24 & 255,62 & & \\
\hline \multirow{5}{*}{$\begin{array}{c}\text { Faktör } 3 \text { - Eğlence ve Hedonik } \\
\text { Değer }\end{array}$} & Okuryazar & 6 & 199,32 & \multirow{5}{*}{14,55} & \multirow{5}{*}{0,18} \\
\hline & İlköğretim & 7 & 251,44 & & \\
\hline & Lise & 199 & 295,61 & & \\
\hline & $\begin{array}{l}\text { Önlisans (2 y1llık) ve } \\
\text { Lisans (4 yıllık) }\end{array}$ & 223 & 280,48 & & \\
\hline & $\begin{array}{l}\text { Yüksek Lisans ve } \\
\text { Doktora }\end{array}$ & 24 & 245,17 & & \\
\hline \multirow{5}{*}{ Faktör 4 - Sosyal Etki ve Bağlanma } & Okuryazar & 6 & 201,13 & \multirow{5}{*}{46,14} & \multirow{5}{*}{0,00} \\
\hline & İlköğretim & 7 & 299,37 & & \\
\hline & Lise & 199 & 315,68 & & \\
\hline & $\begin{array}{l}\text { Önlisans (2 yıllık) ve } \\
\text { Lisans (4 yıllık) }\end{array}$ & 223 & 281,91 & & \\
\hline & $\begin{array}{c}\text { Yüksek Lisans ve } \\
\text { Doktora }\end{array}$ & 24 & 246,13 & & \\
\hline
\end{tabular}

Tablo 10'da görülen Kruskal Wallis testi sonuçlarına göre Swarm kullanma davranışlarını oluşturan faktörlerden; kullanım kolaylığı ile eğlence ve hedonik değer anlamlılık düzeyi (p) arzu edilen \%5'ten büyük olduğu için Swarm kullanıcılarının eğitim durumuna göre farklılık göstermemektedir. Buna karşılık, elde edilen faydalar ile sosyal etki ve bağlanma anlamlılık düzeyi (p) \%5'ten küçük olduğu için Swarm kullanıcılarının eğitim durumlarına göre farklılık göstermektedir. Elde edilen faydalar ile sosyal etki ve bağlanma açısından lise mezunlarının diğer mezunlara göre daha yüksek düzeyde fayda elde ettikleri, sosyal etki ve bağlanma gösterdikleri tespit edilmektedir. Bu sonuçlara göre Faktör 1 ve 3 için $H_{1 d 0}$ kabul edilirken Faktör 2 ve 4 için reddedilmektedir. 
Tablo 11. Swarm Kullanım Alışkanlıklarının Swarm Kullanma Davranışlarını Oluşturan Faktörlere Etkisi

\begin{tabular}{|c|c|c|c|c|c|c|}
\hline & \multicolumn{2}{|c|}{$\begin{array}{c}\text { Standardize } \\
\text { Edilmemiş Katsayılar }\end{array}$} & \multirow{2}{*}{$\begin{array}{c}\text { Standardize } \\
\text { Edilmiş } \\
\text { Katsayılar } \\
\text { Beta }\end{array}$} & \multirow[t]{2}{*}{$\mathrm{t}$} & \multirow[t]{2}{*}{$\mathrm{p}$} & \multirow{2}{*}{$\begin{array}{c}\text { Düzeltilmiş } \\
\mathrm{R}^{2}\end{array}$} \\
\hline & B & Std. Hata & & & & \\
\hline & \multicolumn{6}{|c|}{ Model 1: Bağımlı Faktör Olarak Kullanım Kolaylığı } \\
\hline (Sabit) & 4,85 & 0,91 & & 0,64 & 0,34 & \multirow{3}{*}{0,75} \\
\hline $\begin{array}{l}\text { Swarm kullanarak yer bildirimi } \\
\text { yapma sıklığ1 }\end{array}$ & 1,24 & 0,83 & 0,93 & 45,87 & 0,00 & \\
\hline \multirow[t]{2}{*}{$\begin{array}{l}\text { En çok ne tip mekanlarda yer } \\
\text { bildirimi yapıldığ }\end{array}$} & 1,34 & 0,64 & 0,88 & 33,67 & 0,00 & \\
\hline & \multicolumn{6}{|c|}{ Model 2: Bağımlı Faktör Olarak Elde Edilen Faydalar } \\
\hline (Sabit) & 5,61 & 1,02 & & 0,75 & 0,41 & \multirow{3}{*}{0,73} \\
\hline $\begin{array}{l}\text { Swarm kullanarak yer bildirimi } \\
\text { yapma sıklığ1 }\end{array}$ & 1,43 & 0,69 & 0,92 & 44,56 & 0,00 & \\
\hline \multirow[t]{2}{*}{$\begin{array}{l}\text { En çok ne tip mekanlarda yer } \\
\text { bildirimi yapıldığı }\end{array}$} & 1,35 & 0,71 & 0,83 & 28,09 & 0,00 & \\
\hline & Mod & 3: Bağımlı & aktör Olarak & lence $v$ & Hedo & iik Değer \\
\hline (Sabit) & 5,19 & 1,04 & & 0,69 & 0,29 & \multirow{3}{*}{0,70} \\
\hline $\begin{array}{l}\text { Swarm kullanarak yer bildirimi } \\
\text { yapma sıklığ1 }\end{array}$ & 1,28 & 0,87 & 0,87 & 31,12 & 0,00 & \\
\hline \multirow[t]{2}{*}{$\begin{array}{l}\text { En çok ne tip mekanlarda yer } \\
\text { bildirimi yapıldığı }\end{array}$} & 1,13 & 0,98 & 0,84 & 29,54 & 0,00 & \\
\hline & Mo & 1 4: Bağımlı & Faktör Olarak & osyal Et & i ve B & ğlanma \\
\hline (Sabit) & 4,89 & & & 0,67 & 0,54 & \multirow{3}{*}{0,81} \\
\hline $\begin{array}{l}\text { Swarm kullanarak yer bildirimi } \\
\text { yapma sıklığ1 }\end{array}$ & 1,01 & 0,99 & 0,91 & 41,13 & 0,00 & \\
\hline $\begin{array}{l}\text { En çok ne tip mekanlarda yer } \\
\text { bildirimi yapıldığ } 1\end{array}$ & 1,32 & 1,02 & 0,94 & 47,51 & 0,00 & \\
\hline
\end{tabular}

Tablo 11'de Swarm kullanım alışkanlıklarının Swarm kullanma davranışlarını oluşturan faktörlere etkisi dair sonuçlar görülmektedir. Bu sonuçlara göre Swarm kullanım alışkanlıklarının Swarm kullanma davranışlarını oluşturan tüm faktörlere genel olarak yüksek derecede veya güçlü bir şekilde etkide bulunmaktadır. Dolayısıyla, $\mathrm{H}_{20}$ hipotezi reddedilmektedir. 


\section{Sonuç ve Öneriler}

Bilgi teknolojileri sayesinde mobil uygulamalar sürekli güncellenmekte ve gelişmektedir. Buna paralel olarak bu uygulamaları kullananların sayısı da her geçen gün artmaktadır. İşletmeler ise hem potansiyel müşterilerine hem de mevcut müşterilerine daha yakın olabilmek ve onlara daha iyi hizmet verebilmek için müşterilerin kullandıkları mobil uygulamalarda yer alarak satışlarını artırmayı hedeflemektedirler. Bu durum pazarlama stratejilerinin ya da yaklaşımlarının da çeşitlenmesine ve yenilerinin ortaya çıkmasına neden olmaktadır.

Son dönemlerde pazarlama literatüründe kendine yer bulan yaklaşımlardan biri de lokasyon bazlı pazarlamadır. Mobil uygulamalar sayesinde (örneğin; Swarm ve Facebook gibi) müşteriler yer bildirimi yapmakta ya da cep telefonu operatörleri ile yapılan anlaşmalar ile satın alma noktalarında müşterilere ulaşılabilmektedir. Bu sayede işletmeler yakın çevrelerindeki müşterilerin kimler olduğunu tespit edebilmekte ve onlara ulaşabilmektedir. Yaptıkları kampanyalar ile müşterileri davet edip, satışlarını ve dolayısıyla da karlarını artırmaya çalışmaktadırlar.

Bu noktalardan hareketle gerçekleştirilen çalışmada, lokasyon bazlı pazarlama açısından sosyal ağ uygulamaları ile ilgili kullanım alışkanlıkları ve kullanma davranışları, Swarm uygulamasını kullananlar bazında incelenmiştir. Ortaya çıkan sonuçlar şu şekilde özetlenebilir:

- Swarm kullanıcılarının, \%57,3'ü (263 kişi) kadın ve \%42,7'si (196 kişi) erkeklerden oluştuğu görülmüştür. Yaş dağılımında (\%37,3, 171 kişi) 18 yaş ve altı ve (\%39,2, 180 kişi) 19 - 25 yaş arası kullanıcıların yoğunlukta olduğu tespit edilmiştir. Gelir durumu açısından \%38,1'inin (175 kişi) 1501-2500 TL arası gelire sahip olduğu saptanmıştır. Eğitim durumu açısından ise büyük çoğunluğu ifade eden \%43,4'ünün (199 kişi) lise, \% 48,6'sının (223 kişi) önlisans ve lisans mezunu olduğu belirlenmiş ve bu sonucun yaş dağılımı ile de uyumlu olduğu düşünülmüştür.

- Swarm kullanıcılarının çoğunluğunu oluşturan \%55,8'inin (256 kişi) her gün defalarca Swarm uygulamasını kullanarak yer bildirimi yaptıkları tespit edilmiştir.

- Swarm kullanıcılarının çoğunlukla, \%62,1 oranında (285 kişi) gidilen kafe/restaurant/bar/otel gibi mekanlarda yer bildirim yaptıkları saptanmıştır.

- Swarm kullanım davranışlarına etki eden faktörler; kullanım kolaylığı, elde edilen faydalar, eğlence ve hedonik değer ile sosyal etki ve bağlanma şeklinde sıralanmaktadır.

- Cinsiyet açısından erkeklerin sosyal etki ve bağlanma düzeylerinin kadınlara oranla daha yüksek olduğu belirlenmiştir.

- Yaşa göre kullanım kolaylığı, elde edilen faydalar ile sosyal etki ve bağlanma açısından 1925 yaş aralığının, eğlence ve hedonik değer açısından ise 18 ve altı yaş aralığının diğer yaş aralıklarına göre daha yüksek düzeylerde olduğu tespit edilmiştir.

- Swarm kullanma davranışlarını oluşturan tüm faktörlerin gelir durumuna göre farklılık göstermediği saptanmıştır. 
- Elde edilen faydalar ile sosyal etki ve bağlanma açısından lise mezunlarının diğer mezunlara göre daha yüksek düzeyde fayda elde ettikleri, sosyal etki ve bağlanma gösterdikleri belirlenmiştir.

- Son olarak; Swarm kullanım alışkanlıklarının Swarm kullanma davranışlarını oluşturan tüm faktörlere genel olarak yüksek derecede veya güçlü bir şekilde etkide bulunduğu tespit edilmiştir.

Araştırmada ortaya çıkan sonuçları dikkate alarak bu konuda çalışma yapacaklara bazı önerilerde bulunmak da mümkündür. Bu çalışma Swarm kullanıcıları ile gerçekleştirilmiştir. Yer bildirimi yapma imkanı sağlayan (Facebook, Foursquare gibi) diğer uygulamaları kullananlar ile çalışma, uyarlanarak tekrarlanabilir ve ortaya çıkan sonuçlar karşılaştırılabilir.

Araştırma İstanbul'da yapılmıştır. Başka bir yerde araştırma tekrarlanıp, ortaya çıkan sonuçların il ya da bölge bazında farklılık gösterip göstermediği kıyaslanabilir. Özellikle sosyo-demografik özelliklerdeki farklılıklar bu kıyaslamada üzerinde durulması gereken önemli bir noktadır.

\section{Kaynakça}

Altındal M. Dijital pazarlamada marka yönetimi ve sosyal medyanın etkileri. Akademik Bilişim 2013 - XV. Akademik Bilişim Konferansı Bildirileri, 23-25 Ocak 2013 - Akdeniz Üniversitesi, Antalya, 2013, 1087-1091.

Aydın A. F. Kurumsal itibar açısından sosyal medyaya ilişkin bir değerlendirme. KTÜ, e-kiad İletişim Araştırmaları Dergisi, Sayı: 9, 2015,78-92.

Bakır, N. O, Aydoğan, S. Tüketicilerin Foursquare veya Swarm uygulamalarını kullanarak yer Bildirimi yapma Davranışlarının, marka tutumuna ve satın alma niyetine etkisi. 20. Ulusal Pazarlama Kongresi, Anadolu Üniversitesi - Eskişehir, 2015, 195-209.

Batra, R, Ahtola, O. L. Measuring the hedonic and utilitarian sources of consumer attitudes. Marketing Letters, 2:2, 1990, 159-170.

Battallar, Z, Cömert, M. Tüketicilerin tercihlerinde sosyal medyadaki reklamların etkisi. Turizm Akademik Dergisi, 2 (1), 2015, 39-48.

Bekar, A, Özçetin, Ç. Yiyecek içecek işletmelerinde mobil uygulamaların kullanımı: Foursquare örneği. Gaziantep University Journal of Social Sciences, 14 (2), 2015, 413-430.

Buczkowski, A. Location based marketing: The academic framework. Erişim Mayıs 15, 2017, https://run.unl.pt/bitstream/10362/8314/1/TGEO0070.pdf, 2012.

Çiftçi, Ç. Lokasyon bazlı pazarlama. Erişim Mayıs 11, 2017, https://pazarlamailetisimi.com/lokasyon-bazlipazarlama/, 2016.

Daştan, İ. Konum tabanlı sosyal ağ uygulamalarını kullanma davranışları: Genç kullanıcılar üzerinde bir araştırma. Sakarya İktisat Dergisi, 4, 2015, 31-51. 
EticaretMag. Markalar için lokasyon bazlı kampanya önerileri ve kullanım örnekleri. Erişim Mayıs, 2017, http://eticaretmag.com/lokasyon-bazli-kampanya-onerileri-ve-ornekleri/, 2013.

Gana, M. A, Thomas, T. K. Consumers attitude towards location-based advertising: An exploratory study. Journal of Research in Marketing, Volume 6, No.1, June, 2016, 390-396.

Gündebahar, M, Kuş-Khalilov, M. C. Teknolojik pazarlama üzerine bir inceleme. Akademik Bilişim 2013 XV. Akademik Bilişim Konferansı Bildirileri, 23-25 Ocak 2013 - Akdeniz Üniversitesi, Antalya, 2013, 453-458.

Karimi, B, Yektaei, M. H. Location recommendation based on location-based social networks for entertainment services. ACSIJ Advances in Computer Science: an International Journal, Vol. 4, Issue 1, No.13, January, 2015, 55-64.

Kurtuluş, K. İşletmelerde araştırma yöntembilimi (Araştırma yöntemleri), İşletme Fakültesi Yayın No: 210, İşletme İktisadı Enstitüsü Yayın No:106, İstanbul, 1989.

Mobile Marketing Association. Mobile location based services, marketing whitepaper. Erişim Mayıs 13, 2017, http://www.mmaglobal.com/files/MobileLBSWhitepaper.pdf, 2011.

Reklamcılık ve Marka İletişimi Platformu. Bir banka Swarm yardımı ile nasıl bir kampanya yaratabilir?. Erişim Mayıs 10, 2017, http://moddreport.com/bir-banka-swarm-yardimi-ile-nasil-bir-kampanyayaratabilir/ 2015.

Özkömürcü, H. Swarm'da bir gerilla pazarlama örneği. Erişim Haziran 10, 2016, http://www.pazarlamasyon.com/pazarlama/gerilla-pazarlama/swarmda-bir-gerilla-pazarlamaornegi/, 2016.

Uğurlu, S. Marka iletişiminde, yeni ve sosyal medyada içerik yönetimi. Üsküdar Üniversitesi Sosyal Bilimler Dergisi, Yı1: 2, Sayı: 2, 2016, 203-227.

Tatar, Ş. B, Erdoğmuş, İ. E. Hedonic, utilitarian and symbolic drives behind place check-in activity of mobile consumers. Marmara Business Review, Volume 1, Issue 1, 2016, 63-79.

Voss, K. E, Spangenberg, E. R, Grohmann, B. Measuring the hedonic and utilitarian dimensions of consumer attitude. Journal of Marketing Research, Vol. XL, 2003, 310-320. 
